\title{
A dimensão estética da competência em informação e a leitura do livro de imagem
}

\author{
The aesthetic dimension of information literacy and the reading of the picture book
}

\begin{abstract}
Ana Paula Pereira
Mestranda do Programa de Pós-Graduação em Ciência da Informação da Universidade Estadual de Londrina -

UEL.

E-mail: appuel@yahoo.com.br

Adriana Rosecler Alcará

Doutora em Psicologia pela Universidade São Francisco - USF. Professora do Departamento de Ciência da Informação da Universidade Estadual de Londrina - UEL. E-mail: adrianaalcara@gmail.com
\end{abstract}

\begin{abstract}
Resumo
O livro de imagem é uma narrativa que propicia ao leitor uma experiência diferente de leitura. Para dar sentido ao texto é preciso relacionar o repertório pessoal, as vivências e experiências aos aspectos visuais e estéticos, pois na medida em que o leitor atribui significados, exercita a imaginação e a criatividade. Este estudo analisa como a leitura do livro de imagem pode contribuir para a competência em informação. Parte-se do pressuposto de que o livro de imagem favorece a dimensão estética da competência em informação, tendo em vista que o leitor ressignifica a leitura ao produzir novos sentidos e significados. Trata-se de uma pesquisa bibliográfica realizada na BRAPCI e no Google Acadêmico, que enfoca a dimensão estética da competência em informação, a leitura da imagem e as potencialidades do livro de imagem. Pode-se inferir que as experiências de leitura do livro de imagem podem aprimorar a competência em informação e tornar o ato de ler mais instigante, divertido e interessante.
\end{abstract}

Palavras-chave: Competência em informação. Dimensão estética. Leitura de imagem. Livro de imagem.

\begin{abstract}
The picture book is a narrative that gives the reader a different reading experience. To give meaning to the text, it is necessary to relate the personal repertoire, the living forms and experiences to the visual and aesthetic aspects, because to the extent that the reader attributes meanings, exercises the imagination and creativity. This study analyzes the way in which the reading of the picture book can provide information literacy. It is assumed that the book of images favors the aesthetic dimension of information literacy in view of the reader's re-signification of reading in producing new senses and meanings. It is a bibliographical research made at BRAPCI and Google Scholar that focuses on the aesthetic dimension of information literacy, the reading of the image and the potentialities of the picture book. It can be inferred that the reading experiences of the picture book can improve the information literacy and makes the act of reading more thought-provoking, fun and interesting.
\end{abstract}

Keywords: Information literacy. Aesthetic dimension. Image reading. Picture book. 


\section{Introdução}

A leitura da imagem requer do leitor um repertório pessoal que vai contribuir na construção e na interpretação do texto, assim como a maneira em que são feitas associações e os próprios sentimentos que aparecem ato de ler. Em se tratando do livro de imagem, tudo o que o leitor já possui mais a mensagem do autor favorecem a produção de sentido da narrativa.

A questão que norteia nosso estudo é: De que modo a leitura do livro de imagem pode contribuir para a competência em informação? Partimos do pressuposto de que os leitores podem desenvolver a dimensão estética da competência em informação a partir da leitura do livro de imagem. Entendemos que é uma via dupla: a leitura do livro de imagem promove a dimensão estética da competência em informação, assim como a competência em informação contribui para as habilidades do leitor de livros de imagem.

A dimensão estética da competência em informação está associada a contemplação do belo e da arte e se aprimora com a leitura de narrativas que despertam habilidades e aprendizados, dentre as quais: montar um quebra-cabeça narrativo, desvendar enigmas e solucionar problemas.

$\mathrm{Na}$ medida em que se busca atribuir sentido, à completar elementos, à apreciar e conhecer as técnicas empregadas pelos autores, o leitor resgata dentro de si leituras e experiências ao mesmo tempo em que aprende um modo de ver a vida. Podemos afirmar que o livro de imagem é uma "obra verdadeiramente criativa" porque "[...] traz algum tipo de novidade que nos obriga a rever o que já conhecíamos, dando-lhe uma nova organização" (ARANHA; MARTINS, 1993, p. 338). E para organizar o conhecido ou mesmo o desconhecido é preciso mobilizar a dimensão sensível da competência em informação, ou seja, a dimensão estética.

A competência em informação não se resume ao saber fazer, mas deve ser entendida como conhecimentos, saberes e aprendizados que se renovam sempre. Com o livro de imagem, o leitor se sensibiliza com as cores, o enredo e os personagens que instigam o pensamento e a reflexão. A competência em informação tende a ser favorecida quando o leitor associa suas experiências pessoais, construindo novos modos de ler e de ver. Assim também, o leitor que possui competência em informação encontra no livro de imagem inúmeras possibilidades: sua criatividade e sua imaginação são potencializadas pelos caminhos criados pelo autor e pela obra. 
Entendemos que a competência em informação requer sujeitos que pensem de modo inovador e isso o livro de imagem (pela liberdade de criação) pode propiciar.

O objetivo deste artigo é refletir sobre como a leitura do livro de imagem propicia a dimensão estética da competência em informação. Assim sendo, nossa proposta é demonstrar que a competência em informação contribui para formação dos leitores quando está relacionada à leitura da imagem, isto é, de narrativas repletas de significados e de sentidos que cabe ao leitor atribuir ao pensar, criar, imaginar, aprender, resolver problemas, propor caminhos.

Para este trabalho utilizamos como método a pesquisa bibliográfica, com abordagem qualitativa e de caráter exploratório, em que levantamos e analisamos algumas produções nacionais existentes sobre a temática deste artigo. Na primeira etapa coletamos artigos, dissertações, teses, livros e capítulos, identificados em busca no Google Acadêmico e na Base de Dados Referenciais de Artigos de Periódicos em Ciência da Informação (BRAPCI). As palavras-chave utilizadas foram: dimensão estética, competência em informação, competência informacional e livro de imagem, que foram combinadas com o operador booleano AND nas estratégias de busca. Na segunda etapa realizamos uma leitura dos trabalhos selecionados para localizar informações com o objetivo de estabelecer ligações entre os autores e o nosso tema. O produto resultante dessa análise é a relação entre a dimensão estética da competência em informação e o livro de imagem.

Em nosso ponto de vista, na leitura do livro de imagem o leitor transcende numa experiência enriquecedora para a dimensão estética da competência em informação. Sendo assim, é necessário abordarmos os conceitos de competência em informação e a dimensão estética, os aspectos da leitura da imagem e as possibilidades e potencialidades do livro de imagem. 


\section{A dimensão estética da competência em informação}

Dudziak (2001, p. 77) entende que a competência em informação é "[...] uma forma de conceber nossa interação com o mundo, uma metáfora da própria condição humana de aprendizado permanente [...]". Orelo e Vitorino (2012, p. 47-48) advogam que as definições de competência em informação preocupam-se

[...] em habilitar o indivíduo para o uso eficiente dos recursos informacionais, mais do que habilidades informacionais de caráter 'técnico' (identificar e recuperar a informação), observa-se a preocupação com as questões cognitivas, aquelas relacionadas à compreensão da informação acessada, ou seja, o desenvolvimento do pensamento crítico, da imaginação, da criatividade, da reflexão.

A competência em informação se volta para o conhecer e o saber, estes fundamentais para o fazer. Nessa concepção o pensamento crítico, a imaginação, a criatividade e a reflexão mencionados pelas autoras podem ser desenvolvidos e aprimorados com a leitura. A criatividade, por exemplo

[...] encena uma nova concepção, sob a qual a pessoa passa por um desenvolvimento e por um aprimoramento de suas habilidades criativas mediante as práticas e a formação. A criação deixa de ser uma inspiração e se torna habilidade que pode ser adquirida por meio da preparação da pessoa [...] (FARIAS, 2014, p. 54).

A autora entende que "A criatividade, como qualquer traço ou característica humana, necessita de condições adequadas para que possa desenvolver-se" (FARIAS, 2014, p. 55). Concordamos e acreditamos que o livro de imagem configura-se como uma "condição adequada" e ideal para a formação de leitores e para a criatividade.

Ainda, nos referindo à competência em informação, destacamos Dudziak (2001, p. 146) que a caracteriza por ser

- [...] transdisciplinar, incorporando um conjunto de habilidades, conhecimentos, valores pessoais e sociais;

- [...] um processo de aprendizado contínuo que envolve informação, conhecimento e inteligência;

- permeia qualquer processo de criação, resolução de problemas e/ou tomada de decisões.

Nossa percepção de competência em informação também vai além de um conjunto de conhecimentos para realizar determinadas ações. É saber realizar essas ações com imaginação, criatividade e criticidade (não no sentido de criticar, mas de levantar questões e propor respostas). 
Baseando-se nas ideias de Rios (2010), Duarte e Caldin (2016) afirmam que a competência em informação possui quatro dimensões: a dimensão técnica, a dimensão estética, a dimensão ética e a dimensão política, sendo que

- A dimensão técnica - aborda questões do saber fazer [...];

- A dimensão estética - apresenta a sensibilidade e a consciência de ser sensível ao outro e a si mesmo; dimensão que envolve a sensibilidade [...] e o agir humano, destaca o potencial criativo de cada um;

- A dimensão ética - trata de deixar claro o que pode ou não pode ser feito, o que deve ou não deve ser feito no agir [...] humano; trata da convivência em sociedade e das regras necessárias à coletividade;

- A dimensão política - trata do trabalho desenvolvido pelo indivíduo para o coletivo, em que se observa o potencial do desenvolvimento técnico e criativo voltados para produtos e serviços à disposição do outro (DUARTE; CALDIN, 2016, p. 08).

Nesta perspectiva, a dimensão estética da competência em informação provoca “[...] no indivíduo o desejo pelo aprendizado contínuo, priorizando nesse conjunto os elementos essencialmente humanos, como a sensibilidade, a cognição, a criatividade, a imaginação, o pensamento crítico, a autorreflexão" (ORELO; VITORINO, 2012, p. 53).

Assim, quando dizemos que a competência em informação possui uma dimensão estética, estamos nos referindo às sensações e impressões pessoais do indivíduo em contato com a arte que o leva a ver e agir de um modo novo. De acordo com Vitorino e Piantola (2011, p. 103), "Por meio da sensibilidade e da criatividade demandadas pela arte, o homem sempre buscou atingir ideais de harmonia e beleza essenciais ao bem viver". É por meio da arte que o homem manifesta seu potencial criador, o estado de espírito e ideias.

Na leitura do livro de imagem o leitor tem em mãos uma verdadeira obra de arte em que leitor e autor dialogam, buscando neste diálogo uma intencionalidade. Entretanto, cada leitor pode apresentar um ponto de vista, uma interpretação dos "elementos informacionais" da narrativa. Entendemos que o ato de pensar, refletir, imaginar e criar histórias a partir da leitura de livros de imagem exercitam e promovem a dimensão estética da competência em informação.

Orelo (2013, p. 136) advoga que a dimensão estética da competência em informação "[...] está relacionada à construção de novos conhecimentos, por meio da sensibilidade, da criatividade e das percepções do mundo no qual estamos inseridos, [das] experiências vividas pelo indivíduo". Concordamos com a autora quando diz que a sensibilidade, a criatividade, as percepções e as experiências do indivíduo favorecem a produção do conhecimento. Ademais, 
[...] a própria informação comporta uma dimensão estética, pois transmite-se aos indivíduos tanto a partir de referenciais do mundo exterior, com base em dados empíricos, verificáveis, objetivos, quanto do interior, por meio da intuição, da sensibilidade, da imaginação e da reflexão pessoal. (VITORINO; PIANTOLA, 2011, p. 103).

As autoras defendem a dimensão estética da informação que se constitui no mundo exterior (material) e interior (sentimentos). Assim também a leitura apresenta uma dimensão estética que circula entre esses dois mundos. Portanto, há uma relação entre a dimensão estética da leitura e da competência em informação, uma vez que esta última abrange a "[...] experiência interior, individual e única do sujeito ao lidar com os conteúdos de informação e a sua maneira de expressá-la [...]" (VITORINO; PIANTOLA, 2011, p. 103-104).

A dimensão estética tende a ser favorecida pela leitura do livro de imagem, na medida em que o indivíduo experimenta um modo novo de ler. Trata-se de uma leitura não-linear que requer habilidades de imaginar, criar e relacionar experiências pessoais. Conforme Vitorino e Piantola (2011, p. 103-104) "Ao imaginarmos ou criarmos relações mentais em resposta a uma informação, trazemos à consciência algo de nós mesmos, algo do fundo de nossa vida psíquica, imprimindo-lhe características pessoais [...]". Portanto, ao lidar com a informação (e com a leitura) o indivíduo traz um pouco de si e os sentidos e significados são construídos com elementos inerentes do leitor que, consciente ou não, imprime sua marca.

A leitura do livro de imagem promove a competência em informação ao propiciar a autonomia, o aprendizado e a criatividade. É importante salientar que “[...] não se trata de uma sensibilidade ou de uma criatividade quaisquer, mas de um movimento na direção da beleza, aqui vista como algo que está próximo do que se necessita para o bem social e coletivo" (FARIAS; VITORINO, 2009, p. 7).

Acreditamos que a dimensão estética da competência em informação possibilita-nos refletir sobre a narrativa, ao associar as "informações" ou "pistas" do texto de maneira criativa e surpreendente. Neste processo, nascem novas histórias ricas em detalhes e ideias. Por meio do livro de imagem é possível e também necessário desenvolver competências e habilidades de informação e de leitura, sendo que o leitor pode aprender a lidar com sentimentos de dúvidas e incertezas num primeiro momento.

A competência em informação pode auxiliar na busca por respostas, na ampliação de significados, pois ainda que confuso, o leitor pode "montar o quebra-cabeça" criando novas narrativas com diferentes interpretações. Aliás, há uma intencionalidade na dimensão estética 
que é "[...] fazer menção à presença da sensibilidade e da beleza como elementos constituintes do saber e do fazer do bibliotecário escolar" (FARIAS; VITORINO, 2009, p. 6).

No contexto da biblioteca escolar, leitor e bibliotecário (mediador) se beneficiam desta dimensão durante a mediação da leitura porque este momento torna-se divertido, uma vez que não há um texto fixo para ser seguido e assim sendo, pode-se criar uma narrativa coletiva em que todos participam. A seguir, a figura 1 apresenta os principais elementos da competência em informação dos leitores de livro de imagem.

Figura 1 - Elementos da leitura do livro de imagem que levam a competência em informação

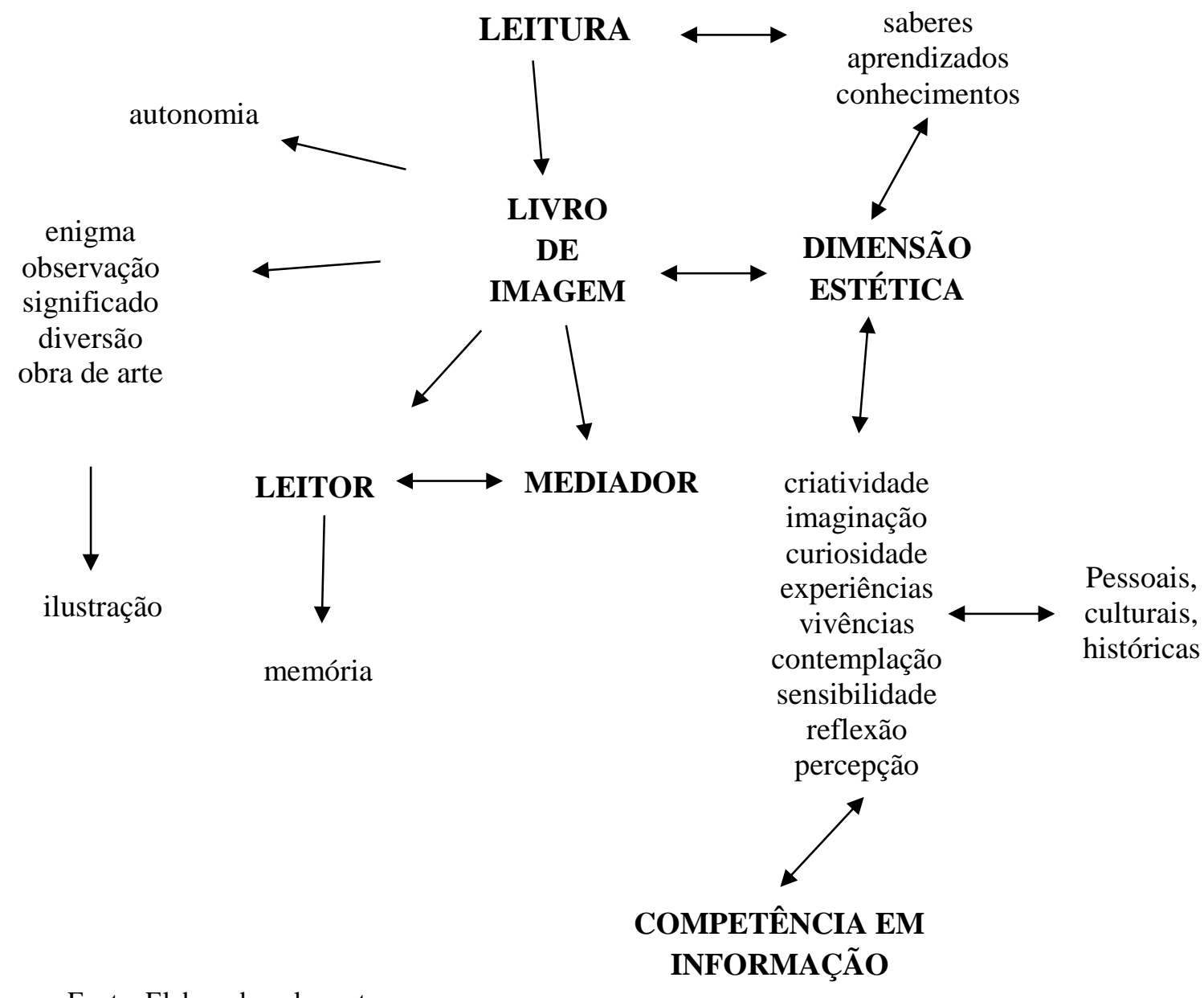

Fonte: Elaborado pelas autoras.

Ao utilizar a criatividade, a imaginação, as experiências e vivências pessoais e a sensibilidade o leitor articula a dimensão estética da competência em informação para ler e desvendar os enigmas do livro de imagem. Nestas narrativas a imagem ou a ilustração nem sempre é simples, e de fácil compreensão. Por isso é necessário entendermos os aspectos da 
leitura da imagem e faremos isso na seção a seguir.

\section{A leitura da imagem}

Neste trabalho adotamos uma concepção ampliada de leitura que transcende a da palavra escrita e abrange a leitura da imagem. Acreditamos que nesta perspectiva a competência em informação fornece as bases necessárias da interpretação, reflexão, entendimento e apropriação da imagem, pois o conhecimento do leitor também advém do texto visual.

No entender de Orelo (2013) a leitura é um dos meios mais eficazes para estimular a criatividade e a imaginação. "Ser curioso, querer aprender, são características notórias nas pessoas esteticamente desenvolvidas, mesmo que elas não tenham a consciência disso" (ORELO, 2013, p. 133). Ainda que inconscientemente, a curiosidade e o desejo de aprender promovem a dimensão estética ao mesmo tempo em que favorecem a interpretação e a apropriação da imagem, aqui entendida como texto.

Ler é um ato complexo, pois "[...] a mente estabelece uma rede associativa intricada e ilimitada, que agrega dispositivos cognitivos, linguísticos, habilidades técnicas e envolvimento emocional, exercendo uma função determinante na aquisição de conhecimento pelo sujeito" (VARELA; BARBOSA, 2012, p. 158).

Nessa concepção de leitura, incluímos a imagem, mais complexa que a palavra devido à carga de subjetividade e da intencionalidade do autor. O leitor precisa estabelecer associações, relações, atribuir sentido, exercitar a imaginação, sem contudo, desconsiderar a carga emocional do texto e o contexto, tendo em vista que "A compreensão completa de textos envolve os processos de recuperar informações, construir uma compreensão geral ampla, desenvolver uma interpretação; refletir sobre o conteúdo de um texto e avaliá-lo" (VARELA; BARBOSA, 2012, p. 158).

Quando mencionamos a leitura da imagem, estamos nos referindo a possibilidade de desenvolver a dimensão estética da competência em informação e a competência em leitura, pois o leitor de imagem sabe pensar por si mesmo, estabelecer relações entre a narrativa, o mundo e sua própria experiência.

Defendemos que a leitura da imagem é diferente da leitura da palavra. Isso porque a imagem muitas vezes não possui linearidade e objetividade, sendo preciso fazer cruzamentos, 
acrescentar elementos. Entretanto, em ambas, o leitor amplia "[...] suas impressões iniciais, de forma a desenvolver uma compreensão mais específica ou mais completa sobre o que foi lido. Nessa categoria é exigida a compreensão [...] os leitores precisam processar a organização da informação no texto" (VARELA; BARBOSA, 2012, p. 158).

$\mathrm{Na}$ leitura do livro de imagem são as impressões do leitor que vão conduzir a interpretação da narrativa. Em nossa visão o cerne da competência em informação é a "[...] autonomia enquanto leitor, no despertar do senso crítico e no exercício da oralidade [...]" (SPUDEIT; COSTA; PRADO, 2012, p. 3). O livro de imagem propicia estes aspectos além de estimular a oralidade, quando os leitores criam narrativas orais, ou no diálogo leitor-mediador.

Com já dito, a leitura da imagem difere da leitura da palavra. Enquanto a palavra direciona a um caminho interpretativo, a imagem "[...] pode apresentar várias camadas de leituras, o que requer daquele que a examina olhar atento e calmo, e aptidão para captar além daquilo que é visto num primeiro momento" (MACHADO, 2014, p. 10).

A aptidão mencionada pelo autor faz parte da competência em informação, quando o leitor articula um conjunto de saberes para examinar e aprofundar-se, pois uma imagem pode estar carregada de subjetividade. "Assim, como o criador da obra convoca toda sua habilidade como artista e contista para oferecer uma história, o leitor tem que valer-se de todas as suas competências narrativas, visuais e até dramáticas para dar essa voz ao texto visual" (SOLANA, 2014). Nessa perspectiva o texto nasce da competência em narrar e dramatizar uma vez que a imagem possui várias "entrelinhas".

Segundo Cunha (2005, p. 27) trata-se de um processo dinâmico em que a criança “"[...] estabelece uma relação com a imagem através da observação, atenção, comparação e contextualização. Para tanto, pressupõe-se uma inter-relação entre o objeto (imagem), a memória do receptor (leitor) e suas experiências". Nesse sentido, a leitura da imagem favorece a dimensão estética da competência em informação, pois o leitor associa a imagem às suas vivências na medida em que observa, compara, contextualiza.

A leitura da imagem pode ser entendida como “[...] um processo contínuo e permanente, que começa no momento em a criança é capaz de perceber sinais e atribuir-lhes significados, e vai acompanhá-la por toda a vida" (CUNHA; SILVA JUNIOR, 2012, p. 127). Um aprendizado ao longo da vida que é um dos princípios da competência em informação. 
É necessário salientar que a leitura da imagem “[...] não precisa ser simplificada, presa apenas ao enredo, porque a imagem não diz tudo, como alguns ainda pensam" (BELMIRO, 2017). Entendemos que cabe também ao mediador de leitura explorar o potencial da imagem e de suas "complexidades".

Ao longo deste trabalho mencionamos o termo livro de imagem. Mas o que seria então um livro de imagem? Para responder, nos apropriamos das palavras de Góes (2003, p. 65): "No livro, o desenho não teria mais o sentido de ilustração do texto, mas passaria a ser o elemento básico e único para estruturar a história. Em resumo, o desenho contaria todo o enredo sem que a palavra escrita entrasse em jogo".

Neste jogo, a imagem/ilustração "substitui" a palavra escrita, por isso, optamos pelo termo de livro de imagem, embora existam outros, como narrativa visual, livro sem texto ou livro sem palavras. De fato,

É quase impossível encontrar um livro [...] que não tenha algumas palavras: na capa (título e nome do autor), na contracapa [...]. É por isto que em inglês são conhecidos, às vezes, como 'livro álbum quase sem palavras' ('nearly wordless picturebook'). Em espanhol se utiliza o termo 'livro álbum sem palavras' e às vezes também 'leitura de imagens' e os italianos utilizam um termo em inglês 'silent books' (livros silenciosos). Esta ideia de livro 'silencioso' ou 'mudo' sugere que é o leitor quem tem que colocar a 'voz'. (SOLANA, 2014).

Embora exista um autor e uma intencionalidade, acreditamos que no momento da leitura a voz e as "ideias" são do leitor. Desse modo, a criança também pode identificá-los como “[...] 'livros de pensar', pois deduz que a imagem é mais aberta do que a palavra, mais plena, mais grávida de sentidos. A imagem não diz o que é para ser lido; ela é sugestiva, expansiva" (RAMOS; PAIVA, 2014, p. 443). De fato são livros que exigem o exercício do pensamento e isso instiga a curiosidade tão necessária para a competência em informação.

O livro de imagem, muitas vezes sugere ao invés de apresentar uma única resposta. Com isso pode-se perceber "[...] elementos contextuais, materiais, discursivos e simbólicos, visto serem eles que geram as possibilidades de significação" (RAMOS, 2014, p. 51). Estas possibilidades e potencialidades enriquecem o momento da leitura e “[...] para a criança pequena ainda é um meio de comunicação fundamental e básico, muitas vezes mais desenvolvido e mais aprimorado que a linguagem verbal” (GÓES, 2003, p. 47).

Apesar de abordamos o livro de imagem para crianças, todas as idades podem beneficiar-se de sua leitura: adolescentes, adultos e idosos. Estas narrativas também têm sido utilizadas na mediação da leitura para crianças surdas, sendo também um material rico para 
pessoas não letradas. Por essa razão toda biblioteca deveria ter um acervo de livros de imagem, já que suas potencialidades e possibilidades fortalecem a dimensão estética dos leitores.

No livro de imagem a tradução se faz desnecessária e isso não impede a compressão do texto como um todo. Assim, a obra original pode "[...] atingir $[\ldots]$ outros países, e, [...] o mais interessante é que os leitores têm acesso às narrativas [...] sem a intermediação do tradutor" (CUNHA, 2005, p. 26). Entretanto, o autor ressalta que a circulação dos livros de imagem “[...] entre leitores de diferentes origens e localidades, [...] não significa que sejam lidos e compreendidos da mesma forma, por todos" (CUNHA, 2005, p. 26). Isso porque a leitura do livro de imagem está diretamente vinculada às experiências pessoais de cada leitor "[...] sua bagagem de vida pessoal, histórica e cultural, possibilitando novas experiências e reelaborações [...]" (CUNHA; SILVA JUNIOR, 2012, p. 128).

As vivências do leitor influenciam a experiência de leitura e para a criança isso é importante porque ela pode imaginar "[...] a história a partir de suas próprias percepções [...]" (MACHADO, 2014, p. 11). Por isso é na infância que a dimensão estética da competência em informação tende a ser mais favorecida, pois nessa fase o imaginário e a capacidade criadora são maiores. Nesse sentido, o livro de imagem pode contribuir, tendo em vista que é "[...] um instrumento de educação ativa, capaz de tocar diretamente a imaginação e a inteligência da criança" (CUNHA; SILVA JUNIOR, 2012, p. 128).

Segundo Lins (2006) “[...] o Brasil [...] é o único lugar do mundo em que o livro vem com uma bula. Ele é acompanhado por uma cartilha de instruções que traz dicas para o professor trabalhar o livro em sala de aula". Acreditamos que a presença desses materiais nos livros de imagem didatiza e limita a narrativa ao direcionar a uma única interpretação, cercada de perguntas e respostas prontas.

Ao contrário, "O maior desafio dos livros de narrativa visual reside na exploração de novas, diferenciadas e criativas formas de narrar [...]" (MACHADO, 2014, p. 12). Esta criatividade é outro componente da dimensão estética da competência em informação que pode ser lapidada na leitura do livro de imagem quando não possui informações explícitas, nem “[...] precisa explicitar todos os sentidos, mas convida, com seus implícitos e suas metáforas visuais, o leitor a pensar, confiando na sua capacidade leitora" (BELMIRO, 2017). Desse modo

Não basta descrever ou enumerar o que se vê, é necessário estabelecer relações entre os elementos, por exemplo, cores, traços, formas. Precisamos perseguir uma cor e tentar entender seu sentido, perseguir uma forma geométrica que tende a se repetir e tentar significá-la. Há livros que [...] utilizam-se de um percurso de leitura que não se 
mostra por meio dessa modalidade discursiva já consagrada; nestes, as imagens vão se apresentando e cabe ao leitor construir um caminho de significação. (RAMOS, 2014, p. 52).

Se não há relação entre os elementos, cenas e personagens, a descrição por si só não levará às possibilidades e aos significados da obra. Assim também as cores e formas não estão ao acaso, por isso "[...] o livro de imagem seria um recurso que, pela ficção e ludismo, contribuiria para a educação do olhar" (RAMOS, 2014, p. 52).

Educar o olhar do leitor (seja criança, adolescente, adulto ou idoso) é necessário para que ele ao observar mais atentamente, consiga além de apreciar, captar o sentido, ir além. Em se tratando da criança, por exemplo, o livro pode estimular “[...] a imaginação e a atividade [...] podendo levá-la, até mesmo, a sentir vontade de pintar, inventar histórias ou brincar [...]" (GÓES, 2003, p. 66).

Para ilustrarmos que a intencionalidade do autor/ilustrador está desde a escolha das cores (que também têm um significado no texto) escolhemos duas imagens extraídas de livros de imagem: a imagem 1 é do livro Lauka e o guarda-chuva (texto e ilustração de Alexandre Camanho, SESI-SP editora) e a imagem 2 do livro $O$ fim da fila (texto e ilustração de Marcelo Pimentel, editora Rovelle). Em ambos há uma intenção na escolha do tom vermelho que aliás os torna mais enigmáticos e instigantes. Além do aspecto estético, o leitor pode se questionar sobre o porquê desta cor nas obras, tanto destacando o guarda-chuva quanto o índio colorindo os animais. No momento em que leitor se questiona e se inquieta também está aprimorando a dimensão estética da competência em informação.

\section{Imagem 1- Guarda-chuva da Lauka}

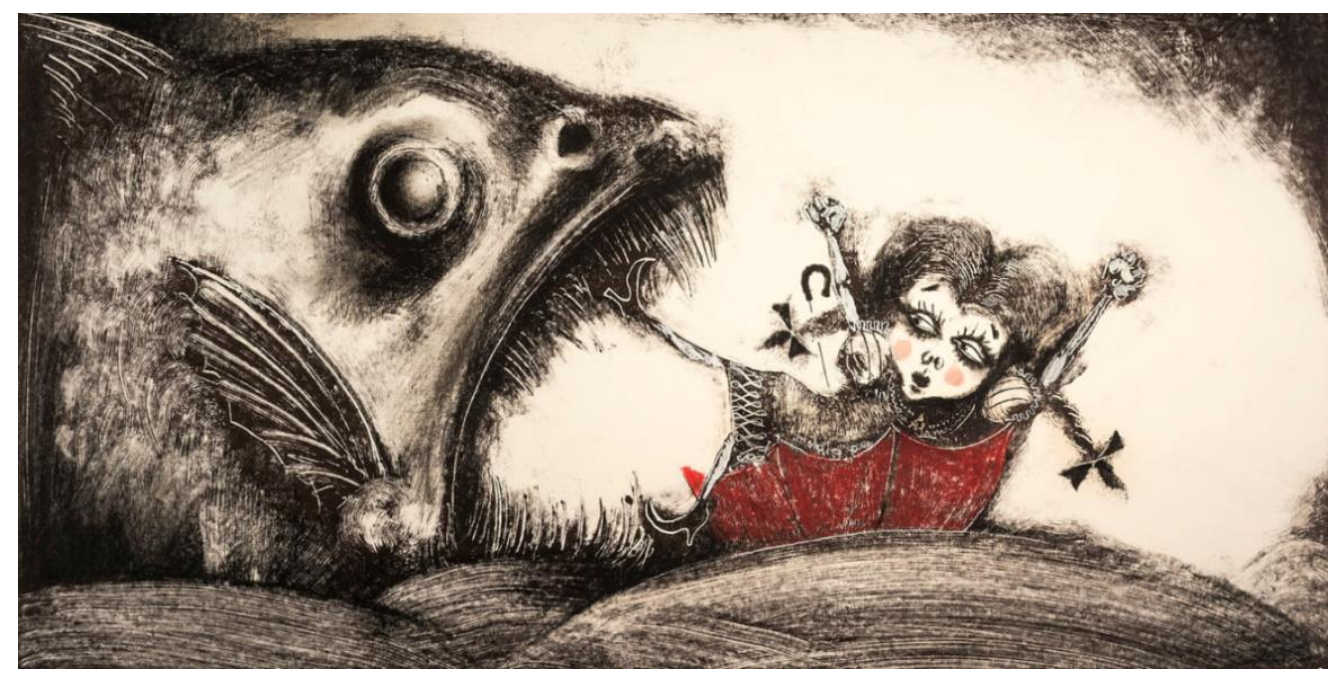

Fonte: CAMANHO, A. Lauka e o guarda-chuva. São Paulo: SESI, 2015. 
Imagem 2 - "Tinta" utilizada pelo índio

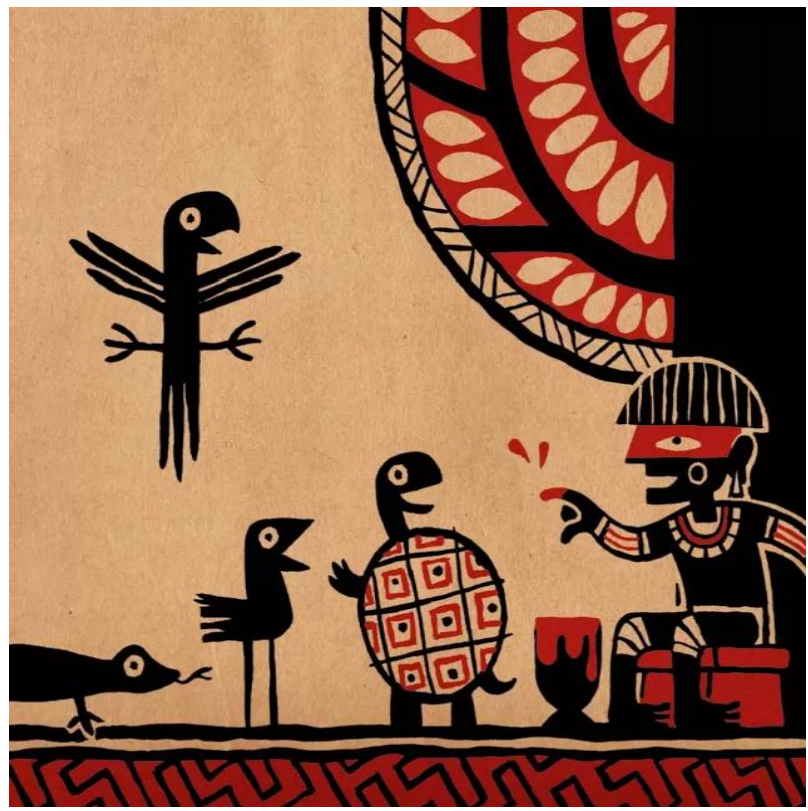

Fonte: PIMENTEL, M. O fim da fila. Rio de Janeiro: Rovelle, 2011.

Além disso, o fato de o livro de imagem " [...] poder contar uma história, de penetrar no mundo do encantamento, faz o tempo do real e da magia conviverem, por exemplo, na mesma página, podendo alterar a lógica temporal e espacial [...]” (BELMIRO, 2017). Neste contexto, entendemos que a dimensão estética da competência em informação se constitui quando o indivíduo traz os elementos da arte, da imaginação, da magia, do brincar para a vida, na resolução de problemas seja dos personagens, seja da realidade.

Assim, reforçamos a relação entre a leitura de imagem e a competência em informação, sendo que tanto a competência em informação contribui para leitura, quanto a leitura de imagem promove a competência em informação, especialmente na dimensão estética. De fato, quando há a possibilidade de uma leitura mais ampla (a exemplo da leitura de imagem) que permite ao leitor utilizar-se da cognição seja no aspecto da criatividade, do pensamento, da imaginação ou mesmo da sensibilidade (sem a qual a apropriação não ocorre em sua plenitude), criam-se os elementos de desenvolvimento da dimensão estética da competência em informação. Do mesmo modo, para ir além daquilo que se vê num primeiro momento, isto é, para apreciar e contemplar o livro de imagem enquanto obra de arte e assim atingir o sensível, a dimensão estética se faz necessária. 


\section{Algumas considerações}

Ao aproximarmos a competência em informação e o livro de imagem procuramos evidenciar que esta narrativa pode estimular a criatividade, a reflexão, o raciocínio, a imaginação, a contemplação do belo diante das informações visuais numa dimensão mais sensível da competência - a dimensão estética. Todas as possibilidades do livro de imagem são aplicáveis à vida do leitor independentemente da idade ou do nível de alfabetização, podendo ser lido por crianças, adultos ou idosos, alfabetizados ou não.

Na perspectiva da competência em informação, mais do que saber fazer é preciso saber ser e saber utilizar o conhecimento advindo de textos que favorecem o protagonismo e a participação do leitor. É válido lembrar que "O conhecimento só pode ser construído se a informação que recebemos tiver valor e significado no contexto do repertório de vivências e conhecimentos que carregamos, permitindo nova interpretação da realidade" (VITORINO; PIANTOLA, 2011, p. 104).

Por meio da arte o homem tem manifestado seus sentimentos mais profundos e isso fica evidente em muitos livros de imagem, principalmente quando os autores abordam a realidade e temas universais. Além da estética e da beleza da imagem, os mediadores de leitura podem levar os leitores à reflexão sobre si mesmo aproximando-os da leitura e da literatura e tornando o ato de ler divertido, interessante e instigante, cuja imaginação e curiosidade são fundamentos da interpretação e da competência em informação. O leitor tornar-se-á um indivíduo competente em informação quando souber articular saberes, vivências e experiências.

A leitura do livro de imagem pode propiciar a dimensão estética da competência em informação quando o leitor tem uma experiência diferente de leitura. Para dar sentido ao texto visual é preciso relacionar o repertório pessoal, as vivências e percepções aos elementos da narrativa como a cor, o traço e a forma. Ao mesmo tempo em que o leitor atribui significados, exercita a imaginação e a criatividade. E para ter criatividade o indivíduo precisa mobilizar várias informações ou um conjunto de informações, que serão possibilitadas por meio da competência em informação.

É importante ressaltar que o livro de imagem enriquece a experiência de leitura do mediador e do leitor. E este último é favorecido de ambos os lados: enquanto leitor tem em mãos verdadeiras obras de arte podendo aprender, criar e imaginar de modo mais livre e 
enquanto sujeito pode desenvolver a criticidade e a criatividade, tão necessárias no mundo atual. E ser criativo nada mais é do que resolver problemas com imaginação.

No livro de imagem, a imagem ou ilustração nem sempre é simples, e de fácil compreensão e isso faz com que o leitor articule a dimensão estética da competência em informação quando desvenda enigmas e interpreta o texto. Na medida em que utiliza a criatividade, a imaginação, as experiências e vivências pessoais e a sensibilidade, leitor e mediador aprimoram a dimensão estética da competência em informação.

\section{Referências}

ARANHA, M. L. A.; MARTINS, M. H. P. Filosofando: introdução a filosofia. 2. ed. São Paulo: Moderna, 1993.

BELMIRO, C. Livro de Imagens. In: CENTRO DE ALFABETIZAÇÃO, LEITURA E ESCRITA. Glossário Ceale: termos de alfabetização, leitura e escrita para educadores. Belo Horizonte: UFMG, 2017. Disponível em: http://ceale.fae.ufmg.br/app/webroot/glossarioceale/verbetes/livro-de-imagens. Acesso em: 25 maio 2018.

CAMANHO, A. Lauka e o guarda-chuva. São Paulo: SESI-SP, 2015.

CUNHA, A. C. Livro de imagem: aprender a ler para aprender a ver. 2005. $100 \mathrm{f}$.

Dissertação (Mestrado em Letras) - Universidade Federal de Pernambuco, Pernambuco, 2005. Disponível em:

https://repositorio.ufpe.br/bitstream/123456789/7978/1/arquivo8404_1.pdf. Acesso em: 25 maio 2018.

CUNHA, G. F.; SILVA JUNIOR, J. A. O livro de imagem na educação infantil: um recurso favorável para despertar o desejo para a leitura. Revista UNI, Imperatriz, n. 2, p.123-135, jan./jul. 2012. Disponível em: http://livrozilla.com/doc/758468/o-livro-de-imagem-naeduca\%C3\%A7\%C3\%A3o-infantil--um-recurso. Acesso em: 25 maio 2018.

DUARTE, E. J.; CALDIN, C. F. Estética: uma dimensão da competência em informação a ser percebida por bibliotecário de biblioteca pública. Informação \& Sociedade: Estudos, João Pessoa, v. 26, n. 2, p. 7-23, maio/ago. 2016. Disponível em: http://www.periodicos.ufpb.br/index.php/ies/article/view/29265/16193. Acesso em: 13 set. 2018.

DUDZIAK, E. A. A information literacy e o papel educacional das bibliotecas. 2001. 187 f. Dissertação (Mestrado em Ciências da Computação) - Universidade de São Paulo, São Paulo, 2001. Disponível em: http://www.teses.usp.br/teses/disponiveis/27/27143/tde30112004-151029/pt-br.php. Acesso em: 12 set. 2018. 
FARIAS, G. B. Competência em informação no ensino de Biblioteconomia: por uma aprendizagem significativa e criativa. 2014. 183 f. Tese (Doutorado em Ciência da Informação) - Universidade Estadual Paulista, Faculdade de Filosofia e Ciências, Marília, 2014. Disponível em:

https://repositorio.unesp.br/bitstream/handle/11449/110383/000795008.pdf?sequence=1\&isAl lowed=y. Acesso em: 13 set. 2018.

FARIAS, C. M.; VITORINO, E. V. Competência informacional e dimensões da competência do bibliotecário no contexto escolar. Perspectivas em Ciência da Informaçãa, Belo Horizonte, v. 14, n. 2, p. 2-16, maio/ago. 2009. Disponível em:

http://www.scielo.br/scielo.php?pid=S1413-99362009000200002\&script=sci_arttext. Acesso em: 23 maio 2018.

GÓES, L. P. Olhar de descoberta: proposta analítica de livros que concentram várias linguagens. São Paulo: Paulinas, 2003.

LINS, G. Entrevista ao site RIO MÍDIA (Centro Internacional de Referência em Mídias para Crianças e Adolescentes). 2006. Disponível em: http://revistapontocom.org.br/edicoesanteriores-entrevistas/livro-infantil-a-importancia-e-o-lugar-da-imagem. Acesso em: 25 maio 2018.

MACHADO, P. H. Livros de narrativa visual no Programa Nacional Biblioteca da Escola (PNBE): uma questão de nomenclatura(s)? In: REUNIÃO CIENTÍFICA REGIONAL DA ASSOCIAÇÃO NACIONAL DE PÓS-GRADUAÇÃO E PESQUISA EM EDUCAÇÃO (ANPED SUL), 10., 2014. Florianópolis. Anais eletrônicos... Florianópolis: 2014. p. 1-21. Disponível em: http://xanpedsul.faed.udesc.br/arq_pdf/441-1.pdf. Acesso em: 25 maio 2018.

ORELO, E. R. M. A dimensão estética (sensível) da competência informacional. 2013. 201f. Dissertação (Mestrado em Ciência da Informação) - Universidade Federal de Santa Catarina, Florianópolis, 2013. Disponível em:

https://repositorio.ufsc.br/bitstream/handle/123456789/122792/323984.pdf?sequence=1\&isAl lowed=y. Acesso em: 23 maio 2018.

ORELO, E. R. M.; VITORINO, E. V. Competência informacional: um olhar para a dimensão estética. Perspectivas em Ciência da Informação, Belo Horizonte, v. 17, n. 4, p. 41-56, out./dez. 2012. Disponível em:

http://portaldeperiodicos.eci.ufmg.br/index.php/pci/article/view/1614/1066. Acesso em: 13 set. 2018.

PIMENTEL, M. O fim da fila. Rio de Janeiro: Rovelle, 2011.

RAMOS, F. B. A literatura me alcança pelas imagens que a constituem: Reflexões epistolares. In: PNBE na escola: literatura fora da caixa. Brasília: Ministério da Educação, Secretaria de Educação Básica, 2014. p. 49-64. Disponível em:

http://portal.mec.gov.br/index.php?option=com_docman\&view=download\&alias $=15608$ guia-ef-leituraforadacaixa-pdf\&category slug=maio-2014-pdf\&Itemid=30192. Acesso em: 25 maio 2018.

RAMOS, F. B.; PAIVA, A. P. M. A dimensão não verbal no livro literário para criança. Revista Contrapontos, Itajaí, v. 14, n. 3, p. 425-447, set./dez. 2014. Disponível em: 
https://siaiap32.univali.br/seer/index.php/rc/article/view/5919/3671. Acesso em: 25 maio 2018.

RIOS, T. A. Compreender e ensinar: por uma docência da melhor qualidade. 8. ed. São Paulo: Cortez, 2010.

SOLANA, E. A. Imagens que convidam a pensar: O "livro álbum sem palavras" e a resposta leitora. Tradução de Sandra Mendrano. Revista Emília, São Paulo, fev. 2014.

SPUDEIT, D.; COSTA, M. P. P.; PRADO, J. M. K. do. Desenvolvimento da Competência em Informação: uma proposta para formação de leitores. In: SEMINÁRIO NACIONAL DE BIBLIOTECAS UNIVERSITÁRIAS (SNBU), 17., 2012. Anais eletrônicos [...] Gramado: UFRGS, 2012. Disponível em: https://www.researchgate.net/profile/Jorge_Prado/publication/280446508_Desenvolvimento da_competencia_em_informacao_uma_proposta_para_formacao_de_leitores/links/55b56cc90 8ae9289a08a6b1e.pdf. Acesso em: 25 maio 2018.

VARELA, A.; BARBOSA, M. L. A. Trajetórias cognitivas subjacentes ao processo de busca e uso da informação: fundamentos e transversalidades. Encontros Bibli: Revista Eletrônica de Biblioteconomia e Ciência da Informação, Florianópolis, v. 17, n. esp. 1, p. 142-168, 2012. Disponível em:

https://periodicos.ufsc.br/index.php/eb/article/view/15182924.2012v17nesp1p142/22730. Acesso em: 25 maio 2018.

VITORINO, E. V.; PIANTOLA, D. Dimensões da competência informacional. Ciência da Informação, Brasília, v. 40, n. 1, p. 99-110, jan./abr. 2011. Disponível em: http://www.scielo.br/pdf/ci/v40n1/a08v40n1.pdf. Acesso em: 25 maio 2018.

\section{Agradecimentos}

Aos autores e ilustradores Alexandre Camanho e Marcelo Pimentel e as editoras SESISP e Rovelle que gentilmente autorizaram a reprodução das imagens de seus livros de imagem Lauka e o guarda-chuva e O fim da fila. 